\title{
Effects of Forest Education Program in Urban Natural Park on Elementary School Students' Academic Stress and Ego-Resilience
}

\author{
Young-Mi Jeong ${ }^{1}$ and Chang-Duck Koo ${ }^{2}$ * \\ 'Department of Forest Therapy, Graduate School, Chungbuk National University, Cheongju 28644, South Korea \\ ${ }^{2}$ Department of Forestry, Chungbuk National University, Cheongju 28644, South Korea
}

\begin{abstract}
The purpose of this study was to investigate the effect of forest education program on elementary school students' academic stress and ego-resilience. The subjects of this study were 20 elementary school boys and girls who applied for a youth group forest experience program in OO-dong, Incheon. The duration of the experiment was 12 weeks from September 2 to November 18, 2017 and each session was held once a week and the run time of a session was 90 minutes. Before and after the implementation of the forest education program utilizing the forest environment of the urban nature park, the test for the academic stress and ego-resilience was conducted and analyzed by the SPSS 22.0 program. As a result, the mean total score of academic stress of elementary school students participating in forest education program was significantly lower than that of the not participating students $(p<.05)$. The effect of increasing ego-resilience was also significant in the sub-factors "interpersonal relationship and optimism" and "emotion control and curiosity" $(p<.05)$. The data shows the forest education program is not only effective on relieving academic stress of elementary school students that cause school maladjustment and anxiety due to excessive academic burden, but is also positively affecting ego-resilience that is the ability to cope with stress. Therefore, it proves that forest education programs are suitable for elementary school students.
\end{abstract}

Keywords: forest activity, stress coping, urban forest

\section{Introduction}

Elementary school students today grow up in too much competition and tend to have more disposition of individualism, which leads them to face difficulty in peer relations. Moreover, due to the excessive academic competition, study-related extracurricular activities, and stress from home and surrounding environment, students show more and more anxious emotions such as maladjustment, depression, outcast, and problem behaviors at school where they spend most of the day, thereby threatening their psychological and mental health (Park, 2013). According to "The Subjective Well-being of Korean Children and Its Policy Implications" published by Korea Institute for Health and Social Affairs in 2015, the academic stress of Korean elementary school students is $50.5 \%$, which is highest among UNICEF surveyed countries. The academic stress of Korean children is $17.2 \%$ higher than the average (33.3\%) and three times higher than the Netherlands with the lowest level of $16.8 \%$ (Kim, 2015). This indicates that academic stress is gradually expanding its scope from middle and high school students to elementary school students. Excessive academic burden gives frustration and stress to students, and the level of stress felt by students has already exceeded the optimum level (Hwang, 2008). However, even

Received: April 9, 2018, Revised: April 13, 2018, Accepted: April 22, 2018

First author: Young-Mi Jeong, E-mail: cozy1018@naver.com, ORCID: 0000-0003-4023-6328

*Corresponding author: Chang-Duck Koo, E-mail: koocdm@chungbuk.ac.kr, ORCID: 0000-0001-9508-8858

C 2018 by the Society for People, Plants, and Environment. This is an Open Access article distributed under the terms of the Creative Commons Attribution Non-Commercial License (http://creativecommons.org/licenses/by-nc/4.0/) which permits unrestricted non-commercial use, distribution, and reproduction in any medium, provided the original work is properly cited. 
though many students are suffering from stress, they have individual differences in how much they overcome such stress. Thus, while some students cope with stress poorly, others do a good job overcoming stress and adjust to their situation.

Ego-resilience is one of the variables that control the influence of stress and help students adjust in such stress (Kim and Kim, 2015). Due to the nature of elementary school students, those with low ego-resilience tend to respond sensitively to stress because they cannot cope properly with surrounding changes or external challenges. Since students with high egoresilience tend to try to endure and overcome stress and not to lose confidence, it is necessary to develop ego-resilience of students so that they can well control and cope with academic stress (Kim, 2017).

Recently, there have been growing needs for the activation of forest education to come up with solutions for various adolescent problems, especially systematic policies that can be implemented in education using abundant forest resources. In 2002, the UN proclaimed the Education for Sustainable Development (UNDESD), and forest education is being generalized in advanced countries like Germany, Japan and the US. In particular, Japan has been actively utilizing forest experience education as a solution for adolescent problems since 2001, and Germany has established and is implementing a certification system for forest education specialists as state and federal government law (Lee, 2017). As the five-day workweek system and creative activities have become more activated, Korea is also showing higher demands for forest experience education. To meet these demands, the Forest Education Promotion Act enacted in 2012 defines forest education as 'education for experiencing, exploring, and learning about various functions of forests to understand the importance of forests, acquire knowledge about forests and develop a proper sense of value' (Korea Forest Service, 2016). Forest education in forests relieves students' stress, provides them with psychological and physiological stability, encourages behavioral changes by developing consideration and understanding, and promotes balanced physical development and immunity by allowing them to play around in nature (Ha et al., 2013). Moreover, these activities enrich sensitivity and personality by stimulating the five senses with active interactions such as breathing in forest environment, encountering the products of nature, voluntarily seeing, touching, listening and feeling them, and exploring them with interest (Nam, 2014). Therefore, forest education is a holistic experience created by the interaction between forests and humans.

Recently there have been studies about the effects of forest education programs for children and adolescents. In the study on the effects of forest healing programs on mental healthy recovery of elementary school students, Kim et al. (2013) came up with the results that forest activities prevent stress and mental/emotional problems of elementary school students, and are effective for mental health recovery of elementary school students whose mental/emotional health is deteriorated. The results also prove that forest experience activities carried out by the lower grades of elementary school gave students the ecological literacy of mutual cooperation between nature and humans, serving as an effective education method for development of emotional intelligence and perception of life respect (Kim, 2011).

However, most studies on elementary schools have been conducted on a specific group of children such as maladjusted children or those from low-income families, and the number is remarkably smaller than studies on preschool children. Furthermore, while there are many studies on daily stress, not many of them are about academic stress, and most are even on middle and high school students but not on elementary school students (Sun and Oh, 2014). Therefore, this study intends to determine the effects of forest education programs in urban natural parks on academic stress and ego-resilience of elementary school students as an effective intervention plan to relieve their academic stress and increase ego-resilience.

\section{Research Method}

\section{Subjects and procedures}

This study was conducted in an urban natural park located in OO-dong, Incheon, once a week for total 12 weeks from 
September 2 to November 18, 2017 with 20 male and female students in Grade 4 of elementary school who participated in a forest experience program carried out quarterly by a youth center. The forest education program was carried out in a large urban natural park of 2.665463 million $\mathrm{m}^{2}$ with facilities such as arboretum, forest experience center for preschool children, and marsh eco park, as well as cherry, metasequoia, acorn, nut pine, maple and cypress as the main species of trees. Since this study is on general elementary school students, the program was accompanied by forest interpreter, youth field specialist, and field trip safety guard. Before the program, we conducted a pre survey on academic stress and ego-resilience. The questionnaire was filled out by the participants in the form of a self-administered survey, and we helped them out in case they had any questions about the items or difficulty in understanding. After total 12 sessions of the program (once a week for 12 weeks) were complete, a post survey was conducted on academic stress and ego-resilience. The participants were observed and recorded in each session in order to examine their changes in each session. The observations were recorded with the help of a graduate student majoring in adolescent education in charge of school environment education for elementary school students.

\section{Program content and composition}

This study analyzed the program that can be applied to academic stress and ego-resilience in this study with reference to academic theses, journals and related books to organize an effective forest education program to reduce academic stress

Table 1. Details of each session program

\begin{tabular}{|c|c|c|}
\hline Session & Program title & Activity contents and purpose \\
\hline 1 & It is beautiful to see in detail. & $\begin{array}{l}\text { Find a natural object that resembles oneself from the forest. } \\
\text { Formation of intimacy with nature and recovery of self-confidence through natural elements. }\end{array}$ \\
\hline 2 & A forest felt with five senses & $\begin{array}{l}\text { Close your eyes, feel the sun and the wind, listen to the sound of the forest. } \\
\text { Psychological stability and relaxation through sunlight and sound. }\end{array}$ \\
\hline 3 & A forest felt with fragrance & $\begin{array}{l}\text { Look for fragrant plants and feel the scent. } \\
\text { Mind and body stimulation and curiosity stimulation through fragrance. }\end{array}$ \\
\hline 4 & A forest felt with touch & $\begin{array}{l}\text { Feel the sense of touch in the soles of your feet by walking barefoot. } \\
\text { Relaxation and mental and physical stability through forest topography. }\end{array}$ \\
\hline 5 & A forest world through mirror & $\begin{array}{l}\text { Enjoy the scenery in the forest using a mirror. } \\
\text { Psychological stability and stress relief through scenery. }\end{array}$ \\
\hline 6 & Finding treasures in the forest & $\begin{array}{l}\text { Find natural things that you think are important in the forest. } \\
\text { Improve problem solving ability by topography and natural elements. }\end{array}$ \\
\hline 7 & The forest in the leaves & $\begin{array}{l}\text { Finding my merit and improving self-confidence through activities with various leaves of } \\
\text { different color, shape and size. } \\
\text { Psychological through seasonal changes. Emotional stability. }\end{array}$ \\
\hline 8 & My own forest & $\begin{array}{l}\text { Create a secret space using trees and branches. } \\
\text { Bonding through natural elements, cultivating cooperation. }\end{array}$ \\
\hline 9 & Expedition to the forest & $\begin{array}{l}\text { Use the ecological map to find the designated point and perform the suggested mission. } \\
\text { Positive relationship formation and challenge awareness through natural elements and } \\
\text { topography. }\end{array}$ \\
\hline 10 & Wisdom learned from forest & $\begin{array}{l}\text { Observe leaves fed by worms and insects. } \\
\text { Psychological and social effects through natural factors. }\end{array}$ \\
\hline 11 & $\begin{array}{l}\text { Making happiness in the } \\
\text { forest }\end{array}$ & $\begin{array}{l}\text { Observe the fruit and use various fruits to complete the work. } \\
\text { Importance of creativity and mutual relationship through natural elements. }\end{array}$ \\
\hline 12 & Living together in a forest & $\begin{array}{l}\text { Use the rope to make an ecological net. } \\
\text { Recognize the importance of interest, confidence, and mutual relationship through nature. }\end{array}$ \\
\hline
\end{tabular}


and improve ego-resilience of elementary school students. In particular, forest play to attract interest in 'Ecological Play Based on Themes from Cartoons' (Hwang, 2009) and 'Kids, Let's Play in the Woods' (Nam, 2006) was commonly applied. Table 1 shows the detailed contents of the program in each session. From the program, 'It is beautiful to see in detail' is organized to give students a chance to look back on themselves by finding a natural object that they think resembles them from the forest, and to build a positive identity by finding their own individuality and listen to what other friends say about it. 'The forest in the leaves' is playing rock-paper-scissors with various shapes of leaves that are an element of the forest. It is organized so that students can explore and prepare their career path by perceiving that they have their own individual personality and can be the best, just as the smallest worm-eaten leaf can win depending on the standard.

\section{Measurement tool}

\section{Academic stress}

Academic stress in this study was measured by the life stress scale of elementary school students developed by Cho (2006) and modified by Kang (2008) by excerpting academic stress factors of the higher grades of elementary school. This scale consists of 4 factors: test/grade, homework, contents to learn, and private educational institute. Test/grade stress, homework stress and private educational institute have 4 items each and contents to learn has 3 items, adding up to total 15 items. Each item is rated on a 4-point Likert scale from 'Strongly agree' (4 points) to 'Strongly disagree' (1 point), with higher scores indicating greater perception of academic stress. The reliability of the academic stress scale in this study is Cronbach's $\alpha .92$, and Table 2 shows the composition of each factor and reliability.

\section{Ego-resilience}

To measure the ego-resilience of elementary school students, this study used the Ego-Resiliency Scale (ER) developed by Block \& Klemen (1996) and translated, modified and improved by Yoo and Sim (2002). This scale consists of 5 factors such as interpersonal relationship, energy, emotion control, curiosity and optimism, but as a result of factor analysis by Park (2011), this study used the scale with 2 factors such as 'interpersonal relationship \& optimism' and 'emotion control \& curiosity.' Each of the total 14 items is rated on a 4-point Likert scale, and it is a self-report scale in which the participants select the items most similar to what they think and feel on a daily basis. The items are rated from 'Mostly disagree (1 point)' to 'Strongly agree (4 points),' with higher scores indicating greater ability to return their emotions to being controllable. The reliability of the ego-resilience scale in this study is Cronbach's $\alpha .92$, and Table 3 shows the items of each factor and reliability.

Table 2. Questionnaire items composition and reliability by sub-factor of academic stress

\begin{tabular}{|c|c|c|c|}
\hline Sub-factor & Items & Number of items & Cronbach's $\alpha$ \\
\hline Test / Grade & $1,5,9,13$ & 4 & .87 \\
\hline Homework & $2,6,10,14$ & 4 & .92 \\
\hline Contents to learn & $3,7,11$ & 3 & .77 \\
\hline Private educational institute & $4,8,12,15$ & 4 & .90 \\
\hline Total & & 15 & .92 \\
\hline
\end{tabular}


Table 3. Questionnaire items composition and reliability by sub-factor of ego-resilience

\begin{tabular}{|c|c|c|c|}
\hline Sub-factor & Items & Number of items & Cronbach's $\alpha$ \\
\hline Interpersonal relationship \& Optimism & $1,2,4,9,12,14$ & 6 & .88 \\
\hline Emotion control \& Curiosity & $3,5,6,7,8,10,11,13$ & 8 & .85 \\
\hline Total & & 14 & .92 \\
\hline
\end{tabular}

\section{Data analysis}

SPSS Windows 22.0 was used for statistical analysis. The Shapiro-Wilk test was conducted to identify the normal distribution, and the paired t-test to verify the effects of the forest education program. The significance level was set at $p$ $<.05$ or lower.

\section{Results and Discussions}

\section{Effects of the forest education program on academic stress of elementary school students}

As for the effects of the forest education program on academic stress of elementary school students, the mean of stress from homework as shown in Table 4 decreased from 3.18 to 2.65 and private educational institute from 2.83 to 2.38 , showing a statistically significant decrease, especially more in homework than private educational institute. The mean also decreased in test/grade and contents to learn, but showed no statistically significant difference. However, overall, the mean score of academic stress after the forest education program showed a statistically $(p<.05)$ significant decrease.

As such, the forest education program reduced stress from homework and private educational institute among academic stress of elementary school students (Table 4). This result is consistent with previous studies proving that a forest education program using an urban forest reduces academic stress of high school students (Park, 2016), that students positively recover negative emotions such as anxiety, tension, depression and stress through a forest healing program by creating empathy and bond with nature (Park, 2013), and that students' psychological stability is increased and stress

Table 4. Pre and post test results on academic stress of participants $(\mathrm{N}=20)$

\begin{tabular}{|c|c|c|c|c|c|c|}
\hline \multicolumn{2}{|l|}{ Sub-factor } & M & SD & $\mathrm{t}$ & df & $p$ \\
\hline \multirow{2}{*}{ Test/Grade } & Before & 2.68 & 0.98 & \multirow{2}{*}{-1.98} & \multirow{2}{*}{19} & \multirow{2}{*}{0.063} \\
\hline & After & 2.36 & 0.98 & & & \\
\hline \multirow{2}{*}{ Homework } & Before & 3.19 & 0.86 & \multirow{2}{*}{-4.10} & \multirow{2}{*}{19} & \multirow{2}{*}{$0.001^{\text {** }}$} \\
\hline & After & 2.65 & 0.97 & & & \\
\hline \multirow{2}{*}{ Contents to learn } & Before & 2.47 & 0.94 & \multirow{2}{*}{-1.42} & \multirow{2}{*}{19} & \multirow{2}{*}{0.173} \\
\hline & After & 2.20 & 0.76 & & & \\
\hline \multirow{2}{*}{ Private educational institute } & Before & 2.84 & 1.11 & \multirow{2}{*}{-2.57} & \multirow{2}{*}{19} & \multirow{2}{*}{$0.019^{*}$} \\
\hline & After & 2.39 & 1.08 & & & \\
\hline \multirow{2}{*}{ Total } & Before & 2.81 & 0.85 & \multirow{2}{*}{-3.12} & \multirow{2}{*}{19} & \multirow{2}{*}{$0.006^{* *}$} \\
\hline & After & 2.41 & 0.87 & & & \\
\hline
\end{tabular}

${ }^{*} p<.05, \stackrel{* *}{p}<<.01$ 
decreased through a forest education program regardless of the season (Cho, 2012). However, the forest education program did not show much effect on test/grade and contents to learn (Table 4). The contents of the academic stress scale consist of test, class and study elements such as 'taking tests often', 'not knowing when I study', and 'not properly understanding the teacher', which shows that the results may be affected by environmental conditions such as the number of tests, and also by applying technical training about learning or a cognitive program. However, this study was focused on relieving symptoms of stress and had limitations in external environment conditions that are difficult to control, thereby not showing effect on stress from test/grade and contents to learn.

\section{Effects of the forest education program on ego-resilience of elementary school students}

As for the effects of the forest education program on ego-resilience of elementary school students, the mean of interpersonal relationship \& optimism as shown in Table 5 increased from 2.8 to 3.2 and emotion control \& curiosity from 2.94 to 3.34 , showing a statistically significant $(p<.05)$ increase.

As such, the forest education program in this study increased ego-resilience of elementary school students (Table 5). The effects of the forest education program on ego-resilience of elementary school students turned out to be statistically significant in ego-resilience 'interpersonal relationship \& optimism' and 'emotion control and curiosity'. This indicates that students sufficiently release negative emotions through various activities and programs such as ecological play, using natural objects, walking barefoot and storytelling in the forest through the program, and increase self-confidence through a sense of achievement, which has a positive impact on ego-resilience. This result is consistent with previous studies proving that emotional sublimation process through activities that express and release suppressed emotions has a positive effect on emotion regulation (Jeong, 2015), that applying forest experience to camp improves self-concept and self-esteem, self-regulation and social adjustment (Shin, 1998), that forest activities reduce students' stress and anxiety while increasing self-esteem (Kim et al., 2015), and that forest experience activities bring positive change to interpersonal relations and promote curiosity about the environment, enthusiastic attitude, and learning motives (Kim, 2014). This supports the study by Lee (2007) proving that forest experience improved children's emotion regulation ability and the study by Kim (2011) proving that it improved optimism, and shows that the forest education program affects emotion regulation by providing the participants with the chance to release negative energy and suppressed emotions.

\section{Analysis of change in the participants in each session of the forest education program}

This study carried out total 12 sessions of the program. The participants were observed and recorded in each session,

Table 5. Pre and post test results on ego-resilience of participants ( $N=20)$

\begin{tabular}{|c|c|c|c|c|c|c|}
\hline Sub-factor & & M & SD & $\mathrm{t}$ & df & $p$ \\
\hline \multirow{2}{*}{ Interpersonal relationship \& Optimism } & Before & 2.80 & 0.76 & \multirow{2}{*}{4.34} & \multirow{2}{*}{19} & \multirow{2}{*}{$0.000^{* * *}$} \\
\hline & After & 3.21 & 0.64 & & & \\
\hline \multirow{2}{*}{ Emotion control \& Curiosity } & Before & 2.94 & 0.66 & \multirow{2}{*}{4.23} & \multirow{2}{*}{19} & \multirow{2}{*}{$0.000^{* *}$} \\
\hline & After & 3.34 & 0.53 & & & \\
\hline \multirow{2}{*}{ Total } & Before & 2.88 & 0.66 & \multirow{2}{*}{4.97} & \multirow{2}{*}{19} & \multirow{2}{*}{$0.000^{*}$} \\
\hline & After & 3.28 & 0.54 & & & \\
\hline
\end{tabular}

${ }^{*} p<.05,{ }^{* *} p<.01$ 
and their responses and changes in each session are as follows.

Session 1: Students were to introduce themselves through natural objects and build intimacy by finding natural objects that they think resemble themselves and talk to others. At first they seemed awkward, but soon they showed interest and energy by watching other participants with more enthusiasm.

Session 2: Students were to lie down in the forest and feel the sound, wind and sunlight of the forest with their five senses. They could not focus well in the activity as they fooled around when lying down, but soon they felt more relaxed as they closed their eyes and concentrated on the sounds as well as the feeling of the wind and sunlight.

Session 3: Students were to find plants with fragrances and smell them, and find out why the plants create such fragrances. When they were given the plant cards to find such plants, they tended to show a hesitant and passive attitude, and seemed to have difficulty finding the right plant according to the plant card.

Session 4: Students were to walk barefoot in the forest and feel their feet. When they were asked to take off their shoes and walk, most of them resisted, saying that it is dirty. But soon they participated with curiosity and concentrated on feeling their feet, and showed a positive attitude saying that they were fine with dirty feet.

Session 5: Students were to look at the scenery in the forest through a mirror and understand the difference in perspective. They were amazed by the scenery and sky of the forest reflected on the mirror, and showed active interest in the scenery.

Session 6: Students were to explore the forest through the cards presented and the mission. When the mission was given, they complained about pressure in performing the task, but tended to show courage and confidence as they began to solve the mission.

Session 7: Students were to use leaves with various shapes that are an element of the forest, and at first they seemed to have no motivation or will in choosing the leaves. But as they experienced the joy of victory during the activity, they gained confidence and began to participate with more enthusiasm.

Session 8: Students were to take part in a team-based physical activity of building a secret hideout using logs and twigs. They showed interest and actively participated from the start, and seemed to get closer with their teammates as they shared their ideas in the process.

Session 9: Students were to take part in a team-based physical activity of exploring the forest with an ecological map to perform the given task. They built a positive relationship within the team by trying to help one another, and showed a sense of achievement and confidence.

Session 10: Students were to understand the relationship between trees and insects. Male students mostly showed great curiosity and enthusiasm about the insects, whereas most female students were passive.

Session 11: Students were to use various fruits in different seasons to make something for their family or friends. They confidently expressed their feelings or opinions as they looked at the exhibits, and also listened attentively to others.

Session 12: Students were to understand the network of interaction within the ecosystem using a rope. Through the activity, they understood the importance of mutual relationship and showed interest and confidence.

As a result of generally analyzing changes in the participants in each session, it was found that most students enthusiastically participated in physically active and adventurous programs with interest and curiosity, and preferred physically relaxing programs using the five senses such as vision, hearing and touch. On the other hand, they did not show interest in sessions that included educational contents linked to related subjects such as cognitive task performance or animals and plants, but instead showed a passive attitude in participation. The students particularly marveled at the sessions dealing with seasonal changes and scenery of the forest, and concentrated on the landscape. This is consistent 
with the effect of restorative environment in the context of the attention restoration theory (ART), which is one of the forest healing theories. The fact that students marveled at the beauty of landscape and felt psychological stability and freedom through activities stimulating the five senses and using forest landscape shows that the forest environment meets three of the four requirements of attention restoration environment such as being away, fascination and compatibility. In a beautiful place, students' sensitivity is stimulated without much effort, and they feel psychologically and emotionally stable, thereby reducing mental fatigue and stress caused by their studies. Furthermore, the fact that they could cooperate and build close relations through forest topography activities and perform the task with a sense of achievement and confidence shows that the forest environment meets the requirements of being away, extent and fascination. This was effective on increasing ego-resilience to relieve academic stress, regain mental/psychological stability, and control and cope with stress by restoring the attention they had lost due to difficulty in smooth peer relations caused by excessive academic competition and extracurricular activities or studies. Therefore, it is important to implement physical activities using various healing factors from the natural environment, sufficiently create a nature-based environment for psychological/ mental stability, and maintain and build a natural environment to restore attention.

The results above show that the forest education program is not only effective on relieving academic stress of elementary school students that cause school maladjustment and anxiety due to excessive academic burden, but is also positively affecting ego-resilience that is the ability to well control and cope with stress, thereby proving that forest education programs are suitable activities for elementary school students.

Furthermore, the results have the following limitations.

First, this study was conducted on 20 male and female students in Grade 4 of elementary school, and thus has limitations in generalizing and applying the effects of this study. Thus, it is necessary to conduct constant research by sampling more diverse subjects considering the regional characteristics and environment.

Second, this study verified short-term effects by carrying out total 12 sessions once a week. Follow-up research on long-term programs is necessary, as well as research on continuous effects even after the program.

Third, this study was conducted only on Grade 4 elementary school students, and thus it is necessary to develop various forest education programs suitable for the growth and development stages of elementary school students.

\section{Conclusion}

This study is to determine the effects of a forest education program using the forest environment of an urban natural park on academic stress and ego-resilience of elementary school students. The subjects are 20 male and female students in Grade 4 of elementary school that applied for a forest experience program at a youth center located in OO-dong, Incheon. The experiment was conducted in 12 sessions, once a week from September 2 to November 18, 2017, with each session lasting for 90 minutes. The forest education program included elements stimulating the five senses such as vision, hearing, touch and smell; forest landscape elements such as seasonal changes, mystery of nature, and beauty of forest landscapes; topographical elements such as walking and exploring; and ecological and natural elements. The effects of this program were analyzed with SPSS 22.0 by conducting a survey on academic stress and ego-resilience before and after the program. Most elementary school students participating in each session actively participated in physically active and adventurous programs with interest and curiosity, and preferred forest landscapes as well as physically and psychologically relaxing activities using the five senses. On the other hand, they showed no interest in programs including educational contents linked to related subjects such as cognitive task performance or animals and plants, and instead showed a passive attitude in participation. As a result, academic stress of elementary school students that participated in the forest education 
program $(p<.05)$ significantly decreased from homework and private educational institute. However, there was no significant difference in stress from test/grade and contents to learn. This program also significantly $(p<.05)$ increased ego-resilience in the factors such as "interpersonal relationship \& optimism" and "emotion control \& curiosity".

\section{References}

Block, J. and A.M. Kreman. 1996. IQ and ego-resiliency: Conceptual and empirical connections and separateness. J. Pers. Soc. Psychol. 70(2):349-361.

Cho, B.H. 2006. Development of daily hassles scale and daily hassles coping behaviors scale for elementary school children. Korean J. Child Educ. 15(3):5-21.

Cho, Y.M. 2012. The influence of forest experience program on sociality and depression, anxiety of children from low income families. Master's thesis, Chungbuk National University, Cheongju, Korea.

Ha, S.Y., J.J. Kim, and J.W. Son. 2013. Forest, bringing up human. Seoul, Korea: Korea Forest Research Institute.

Hwang, K.T. 2009. Ecological Play Based on Themes (pp.145-263). Seoul, Korea: Slow \& Steady.

Hwang, Y.J. 2008. The determinants of perceived academic stress as experienced by high school students. Stud. Korean Youth. 19(3):85-114.

Jeong, Y.M. 2015. The effect of group art therapy using games on resilience of maladjusted elementary school children. Master's thesis, Konkuk University, Seoul, Korea.

Kang, M.J. 2008. Cognitive behavioral study stress coping training for elementary school children: Effects on study stress and academic self-concept. Master's thesis, Gongju National University of Education, Gongju, Korea.

Kim, J.Y., C.S. Shin, P.S. Yeoun, J.Y. Yi, M.R. Kim, J.K. Kim, and Y.H. Yoo. 2013. Forest healing program impact on the mental health recovery of elementary school students. J. Korean Inst. For. Recreat. 17(4):69-81.

Kim, K.Y. 2011. The influence of forest experience activities on the children's sensitivity and respectful recognition of life. Master's thesis, Dongguk University, Seoul, Korea.

Kim, M.H. 2014. A study on the positive effects of forest activities for children from economically underprivileged households on their emotional state, life satisfaction, and ego-resilience. Korean J. Child Stud. 35(4):223-247. DOI:10.5723/KJCS.2014.35.4.223

Kim, M.S. 2015. The subjective well-being of Korean children and its policy implications. Health Welf. Policy Forum by Korean Inst. Health Soc. Aff. 220:14-26.

Kim, S.A., D.W. Joung, D.G. Yeom, G.W. Kim, and B.J. Park. 2015. The effects of forest activities on attitudes toward forest, stress, self-esteem and mental health of children in community child centers. J. Korean Inst. For. Recreat. 19(3):51-58.

Kim, S.J. and S.H. Kim. 2015. The moderating effects of ego-Resilience on the relationship between academic stress and school adjustment of elementary school children. Korean J. Youth Stud. 22(2):49-70.

Kim, S.H. 2017. Effects of group art therapy on ego-resilience and academic stress of elementary school students. Master's thesis, Myoungji University, Seoul, Korea.

Kim, Y.S. 2011. The influence of forest therapeutic program on the depression and self-esteem of middle school students in WEEclass. Master's thesis, Chungbuk National University, Cheongju, Korea.

Korea Forest Service. 2016. Forest education. Retrieved from http://www.forest.go.kr

Lee, O.J. 2007. Effect of integrative education program through school forest on the emotional intelligence of children. Unpublished master's thesis, Gyeongin National University of Education, Incheon, Korea.

Lee, S.H. 2017. A study on developing and applying a forest experience Program to improve core competence of elementary school students. Doctoral dissertation, Daegu Haany University, Gyeongsan, Korea. 
Nam, H.C. 2006. Kids, Let's Play in the Woods(pp.128-343). Seoul, Korea: Chusubat by Chungrim Publishing.

Nam, S.J. 2014. Effects of the forest experience activities on personality of elementary and middle school students. Master's thesis, Sangji University, Wonju, Korea.

Park, J.H. 2013. Effects of forest healing program on elementary school students' self-esteem. Master's thesis, Seoul National University of Education, Seoul, Korea.

Park, K.J. 2016. Effects of forest education program utilizing the urban forest on environmental sensitivity, academic stress and academic achievement of high school students. Master's thesis, Chungbuk National University, Cheongju, Korea.

Park, M.S. 2011. The relationship among the child's stress, ego-resilience and school life adaptation. Master's thesis, Keimyung University, Daugu, Korea.

Shin, W.S. 1998. Meaning and value of forests in urbanized environment. For. Cult. 7(3):20-23. Retrieved from http://www.humantree.or.kr

Sun, H.Y. and J.H. Oh. 2014. Analysis of research in academic stress of elementary school students. J. Educ. by Gyeongin National University of Education 34(2):71-89.

Yoo, S.K. and H.W. Sim. 2002. Psychological protective factors in resilient adolescents in Korea. Korean J. Educ. Psychol. 16(4):189-206. 